140 | Japanese Language and Literature

speaker's hesitation to decline an offer (pointed out by Sadanobu and Shimizu in the volume as "being disfluent") in order to show his/her consideration for the interlocutor. Another example is that the combination of no da and ne/yo, which as Saigō points out, can be introduced to practice conversation in which one tells a short story. Although it is important to instruct and guide learners with materials and language appropriate for the learners' level, instructors should include in their lessons the crucial features that make discourse coherent, cohesive, and effective as communication. Discourse and Proficiency successfully provides instructors with multiple ways to improve learners' proficiency in Japanese.

This volume urges instructors to apply the new perspectives on discourse in their Japanese language instruction from the very beginning in the elementary-level classrooms by reviewing the materials as a part of their day-to-day classroom interactions. Even though it is challenging to teach and guide learners to acquire the skills and knowledge so they can deal with dynamic and real conversational flow, Discourse and Proficiency can be used as resource to help instructors reach these goals in their classrooms. Discourse and Proficiency also reminds us of the constant need for us to go beyond survival level communication in our teaching.

\title{
Ecocriticism in Japan
}

Edited by Hisaaki Wake, Keijiro Suga, and Yuki Masami. New York: Lexington Books, 2018. 296 pp. \$90.00.

\section{Reviewed by Carin Holroyd}

For a scholar outside the field of ecocriticism, it is somewhat surprising to discover how much this is a contested terrain. The intersections of ecology, ecological understanding, culture and national/regional values have created remarkable intellectual diversity and substantial debate about the potential for academic unity in the area. This substantial and fascinating collection, Ecocriticism in Japan, is dedicated to the search for a Japanese conceptualization of ecocriticism. The work differentiates between 
scholars in Japan who write about ecocriticism and those who focus on the uniquely Japanese characteristics of ecocriticism.

This set of papers, in the words of co-editor Yuki Masami, addresses what she describes as "the third phase of ecocriticism in Japan, demonstrating how ecocritical theory and practices interface and negotiate with Japanese literature while anticipating an emergence of Japanese ecocriticism." These are important steps in scholarship, as academics within one nation respond, first, to newly developed theories, methodologies and conceptual frameworks, transitioning to comparative studies that connect, in this instance, Japanese examples with international models, and then continue on to the development of a Japan-specific formulation of ecocriticism.

Ecocriticism in Japan emerges, then, as something of a test of concept. The editors challenged fourteen authors to tackle the issues, locating the theoretical formulation within the Japanese literary context. The work started in two sessions of the American Comparative Literature Association (held in 2015 and 2016) with the contributions of some of the initial contributors expanded through the inclusion of other scholars. This book, then, is more than a report from the intellectual field and more than simply a publishing opportunity that gives scholars an opportunity to publish articles on an important topic. Instead, it is a deliberate attempt to test the concept of a Japanese ecocriticism and to define and shape this emerging sub-field. In the end, the editors and their well-selected team of authors succeed in their task, producing a collection that does a fine job of drawing out the Japanese elements of contemporary ecocriticism.

The collection begins with Masami's short but effective exploration of the changing nature of "harmony" in Japanese critical thought. It continues through a series of fourteen papers that cover such diverse topics as an ecocriticism evaluation of The Tale of Genji, Murakami Haruki's take on the interplay of nature and disaster, Japanese artists after the 3/11 disasters, and the imaginatively titled "Chaosmos of Condivision" that explores the presentation of "radiation aesthetics" in the Coppelion TV series. The collection ranges widely over time and means of artistic expression, looking at the reaction to natural disasters, evolving popular culture, and a reassessment of familiar classics. They reveal, individually and collectively, the authors' detailed understanding of Japanese artistic and literary forms, sophisticated appreciation for the intricacies of naturehuman interactions, and show a rich pattern of theorizing about the 
142 | Japanese Language and Literature

intersection of Japanese scholarship and international patterns of ecocriticism.

The book makes a significant and broad contribution by moving beyond the standard and rather simple characterization of Japanese "harmony with nature." This longstanding concept has always been near the center of the global understanding of Japan, offsetting criticism of the country's extensive industrial past, a series of ecological disasters of dramatic proportions, and Japan's extended infatuation with high technology. Japan has long shown a rich literary interest in nature, artistic traditions that focus on human-nature interactions, and the continued celebration of parks, gardens, wilderness and other natural spots. The "harmony with nature" meme has become a somewhat unexplored staple of efforts to understand and describe Japan. Several of the articles in this collection examine this standard assumption through literary analysis, providing a welcome offset to the standard impression of Japanese connectivity to the environment.

This collection, in the end, is targeted at a very narrow audience, specifically literary analysts with an established interest in ecocriticism. In terms of the editors' main objectives, the volume achieves a great deal. The book will-and should - also attract interest from international scholars of ecocriticism. Some will be challenged to determine if the Japanese scholarship encourages writers in other nations to identify nation or culture-specific ecocriticism. Others, no doubt, will challenge the assumptions about cultural and national differences that underlie this volume. The resulting debate should be the kind of evidence-based and creative discussion that enriches our understanding of human-nature interactions and of how evolving artistic and literary forms reveal the inner workings of national societies.

This intellectual project is well framed, nicely constructed, and well presented. It is, however, quite narrow in conception and design. It would have helped if the editors had provided more guidance for people outside the precise confines of the ecocriticism debate. The themes explored in this book are of broader significance. Ecocriticism in Japan speaks to critical questions about culture and scholarship, the foundational meaning of "Japaneseness," the flow of ideas and theories across and between cultures, and the critical underlying questions about the cultural rootsand implications - of Western/American-based theorizing. These themes show up, more implicitly than explicitly, throughout the papers in the collection. An effort to build on and explain the significance of these 
interesting essays would have given the book even greater currency and impact. As it is, Ecocriticism in Japan is an insightful and important exploration of the intellectual evolution and nature of ecocriticism in contemporary Japan.

As a technical work of scholarship, Ecocriticism in Japan has some of the weaknesses and many of the strengths of a well-edited collection of essays. Collections sit oddly within the world of scholarly communications. Rare sets of papers attract attention as a collective, setting the stage for scholarly re-examination and sparking sustained debate and analysis. More commonly, excellent individual pages can easily be lost in the table of contents of a diverse and uneven set of papers. New distribution systems make it easier for scholars to find and gain access to individual essays, but the larger challenges posed by collections of essays remain. In this instance, the editors clearly understood the dangers associated with inchoate collections. They focused on a specific theme, challenged the authors to direct their attentions to the challenges associated with ecocriticism, and produced a collection that makes a contribution to the redefinition of a sub-field in literary and artistic studies.

In this instance, the papers hang together rather roughly; they are examples of ecocriticism rather than a well-structured and systematic analysis of the theme. As a result, the coverage is inevitably spotty and, in this instance, tilted rather heavily toward the contemporary period. This deliberately diverse approach results in a collection that covers popular and classical literature, emphasizes the environmental and cultural implications of the March 2011 disaster, and that delves into literature, television programing, anime and other forms of artistic expression. The response to the book will be highly individualized, reflecting the diverse needs of the readers as much as the designs and strategies of the editors and authors.

Several papers stood out to this reader. Kyoko Matsunaga's discussion of "radioactive discourse," Alex Bates's study of the literary reaction to the Great Hanshin-Awaji earthquake (1995), and Hisaaki Wake's chapter on the "ideological manipulation" of nature in Japanese popular culture, resonated strongly, primarily because of their intersection with the popular attempts to understand natural phenomenon. Within the collective, multiple authors explore works that are not explicitly ecological in orientation, showing that an ecocriticism perspective can shed new light on familiar texts. The book was not intended to be a comprehensive and text-book style elucidation of the field. Rather, it sought to demonstrate 
144 | Japanese Language and Literature

the broad utility of ecocriticism as an intellectual approach and to encourage authors to search for the Japanese elements of global ecocriticism theory.

Ecocriticism in Japan is not a readily accessible book. It is strongly theoretical in nature, and it is written with a highly specialized audience in mind. Beyond the strong conceptual elements, the volume offers detailed analysis of a wide-range of literature and artistic productions. The authors clearly understand Japan well and bring a great number of critical insights to the conversation. For authors outside of literacy criticism and ecocriticism, the book does an excellent job of demonstrating the challenges and benefits of evaluating an international conceptual field from a national perspective. From the outset, the editors sought to determine the Japanese contribution to a vital global field, to understand if there is an emerging subfield of Japanese ecocriticism, and to ascertain the degree to which ecocriticism elucidates the essence of Japanese cultural, values and relationship with nature. This is an ambitious agenda, one that Ecocriticism in Japan tackles with verve and real energy. While far from the final word on a topic of likely growing importance, the book is an excellent start to the conversation.

\section{Perfumed Sleeves and Tangled Hair: Body, Woman, and Desire in Medieval Japanese Narratives}

By Rajyashree Pandey. Honolulu: University of Hawai'i Press, 2016. xii, 209 pp. $\$ 28.00$.

\section{Reviewed by \\ Kim Mc Nelly}

What modern assumptions have we unwittingly brought into the discussion of medieval Japanese bodies and women? Rajyashree Pandey's Perfumed Sleeves and Tangled Hair: Body, Woman, and Desire in Medieval Japanese Narratives skillfully traces the relevant religious and ideological factors influencing Western discourse on the body, gender, eroticism, and agency to expose the many assumptions that underlie these modern analytical frameworks. She offers an East Asian paradigm based on Buddhist, medical, and philosophical traditions as a new basis for 